\title{
KKN-M Pemanfaatan Waktu Luang dengan Melakukan Bimbingan Belajar bagi Siswa di Desa Ndetundora 1 di Masa Pandemi Covid-19
}

\author{
Emiliana Vivintha Yoman ${ }^{1}$, Maimunh H Daud2*, Maria Waldetrudis Lidi ${ }^{3}$ \\ 1,2,3Universitas Flores, Ende, Indonesia \\ *Corresponding Author: maimunahdaud07@gmail.com
}

\begin{abstract}
Info Artike1 Diterima : 23/10/2021 Direvisi: 25/10/2021 Disetujui: 29/10/2021
Abstract. Ndetundora 1 village is one of the villages in Nuabosi, precisely in Ende sub-district, in independent real work lectures (KKN), students motivate the importance of learning even during the covid 19 pandemic. The purpose of implementing this program is for students to gain learning experiences through direct involvement in the community to find problems in people's lives. In this activity, the problems encountered included a network that was difficult to access which made it difficult for students to study online during a pandemic. In addition, there were also many students who did not use their free time to study. The first step is to record students who are doing online and offline learning. The solution offered in solving problems that have been identified is to conduct learning from home (BDR) using technology media in the form of learning videos. Not only that, but another solution is to conduct tutoring in schools using a scientific approach and contextual or real media.
\end{abstract}

Keywords: Learning from Home, Tutoring, Technology Media

\begin{abstract}
Abstrak. Desa Ndetundora 1 merupakan salah satu desa yang berada di Nuabosi, tepatnya di kecamatan Ende pada kegiatan kuliah kerja nyata $(\mathrm{KKN})$ mandiri, mahasiswa memberikan motivasi pentingnya belajar walaupun disaat pandemic covid 19. Tujuan pelaksanaan program ini agar mahasiswa memperoleh pengalaman belajar melalui keterlibatan dalam masyarakat secara lansung untuk menemukan permasalahan dalam kehidupan masyarakat. Pada kegiatan ini masalah yang ditemui antara lain jaringan yang sulit untuk diakses yang membuat siswa siswi kesulitan belajar online disaat pandemic. Selain itu ditemukan juga banyak siswa siswi yang tidak memanfaatkan waktu luang untuk belajar. Tahapan pertama yang dilakukan adalah mendata siswa siswi yang melakukan pembelajaran online dan offline. Solusi yang ditawarkan dalam pemecahan masalah yang temukan sudah teridenfikasi adalah melakukan bimbingan belajar dari rumah BDR) dengan mengunakan media teknologi berupa video pembelajaran. Bukan hanya itu saja tetapi solusi lainya yaitu melakukan bimbingan belajar di sekolah dengan menggunakan pendekatan saintifik dan media konstekstual atau nyata.
\end{abstract}

Kata Kunci: Belajar dari rumah, bimbingan belajar, media teknologi

How to Cite: Yoman, E. V., Daud, M. H., \& Lidi, M. W. (2020). KKN-M Pemanfaatan Waktu Luang dengan Melakukan Bimbingan Belajar bagi Siswa di Desa Ndetundora 1 di Masa Pandemi Covid-19. Prima Abdika: Jurnal Pengabdian Masyarakat, 1(4), 152-157. https://doi.org/10.37478/abdika.v1i4.1302

(7) (2) Copyright (c) 2021 Emiliana Vivintha Yoman, Maimunh H Daud, Maria Waldetrudis Lidi. This work is licensed under a Creative Commons Attribution-ShareAlike 4.0 International License.

\section{Pendahuluan}

Desa Ndetundora1 merupakan salah satu desa yang berada di Nuabosi, tepatnya di kecamatan Ende, Kabupaten Ende. Batas wilayah desa Ndetundora 1 sebelah utara berbatasan dengan Desa Randotonda, sebelah selatan berbatasan dengan Kelurahan Reworena, sebelah timur berbatasan dengan Desa Kedebodu, dan sebelah barat berbatasan dengan Desa Ndetundora III. Pembagian Wilayah administrasi desa terdiri dari 2 dusun yaitu dusun Pu'uperi dan dusun Nuabosi. Luas wilayah Desa Ndetundora 1 kurang lebih $5.900 \mathrm{Ha}$. Jumlah penduduk berdasarkan Kepala Keluarga (KK) adalah berjumlah $172 \mathrm{KK}$, sedangkan berdasarkan jumlah jiwa Desa Ndetundora 1 berjumlah 671 jiwa yang terdiri dari 304 laki-laki dan 367 perempuan.

Penduduk desa Ndetundora 1 umumnya bekerja sebagai petani. Berikut ini perincian menurut kelompok mata pencarian dan pendidikan. 
Data penduduk menurut mata pencarian : petani 359 orang, pedagang 17 orang, PNS 8 orang, TNI/Polri 2 orang, ibu rumah tangga 27 orang dan lainnya 46 orang. Berdasarkan kelompok pendidikan : SD 87 orang, SMP 37 orang, SMA/SMK 33 orang dan Diploma 1 orang.

Pada kegiatan kuliah kerja nyata (KKN) mandiri ini, mahasiswa mengambil tema Inovasi dan Teknologi Pembelajaran. Dari tema tersebut mahasiswa memberikan motivasi pentingnya belajar walaupun disaat pandemic Covid-19. Tujuan pelaksanaan program ini agar mahasiswa memperoleh pengalaman belajar melalui keterlibatan dalam masyarakat secara lansung untuk menemukan permasalahan dalam kehidupan masyarakat. Pada kegiatan ini masalah yang ditemui antara lain jaringan yang sulit untuk diakses yang membuat siswa siswi kesulitan belajar online disaat pandemic. Selain itu ditemukan juga banyak siswa siswi yang tidak memanfaatkan waktu luang untuk belajar.

Kegiatan KKNM ini bermaka untuk menerapkan ilmu pengetahuan yang diperoleh mahasiswa selama kuliah di kampus. Agar pengetahuan dapat bermanfaat maka pengetahuan itu harus diterapkan di tengah masyarakat (Londa et al., 2021). Ilmu pengetahuan yang dimilki secara moral harus ditunjukan untuk kebaikan manusia tanpa merendakan martabat atau mengubah hakikat manusia (Irwanto, 2017). Dengan bekal ilmu pengetahuan yang diterima dan kemampuan teknologi yang dimiliki mahasiswa diharapkan dapat memberikan solusi dalam menangani masalah yang dihadapi oleh masayarakat.

\section{Metode Pelaksanaan}

Pelaksanaan kegiatan dilaksanakan oleh mahasiswa KKN bersama dengan siswa siswi sekolah dasar dan siswa siswi SMP sejak tanggal 01 Agustus - 31 Agustus 2021. Kegiatan ini berlangsung disekolah maupun disalah satu rumah siswa. Pelaksanaan KKNM di bagi menjadi beberapa tahapan. Tahapan pertama mahasiswa mengumpulkan data siswa siswi yang melakukan pembelajaran online dan siswa siswi yang tidak melakukan pembelajaran secara online. Data yang berhasil dikumpulkan mahasiswa, kemudian di diskusi bersama dengan aparat desa setempat guna mendapatkan persetujuan untuk menjalakan kegaiatan. Hasil olahan data tersebut digunakan untuk membuat program kerja selama mahasiswa melakukan KKNM di desa Ndetundora 1 satu selama satu bulan.

Program kegiatan kemudian disusun berdasarkan hasil olahan data. Solusi yang ditawarkan dalam pemecahan masalasah yang temukan sudah teridenfikasi adalah melakukan bimbingan belajar dari rumah (BDR) dengan mengunakan media teknologi berupa video pembelajaran. Bukan hanya itu saja tetapi solusi lainya yaitu melakukan bimbingan belajar di sekolah dengan menggunakan pendekatan saintifik dan media konstekstual atau nyata. Selain kegiatan tersebut mahasiswa juga melakukan kegiatan pendukung yakni membantu pembuatan administrasi desa, kerja bakti, sosialisasi pencegahan Covid-19, pembagian logistic dan mendemostrasikan bagaimana cara mencuci tangan yang baik dan benar. 


\section{Hasil dan Pembahasan}

Kegiatan KKNM dilaksanakan mahasiswa bersama dengan dosen pembimbing lapangan (DPL) di desa Ndetundora 1,Kecamatan Ende, Kabupaten Ende mulai dari tanggal 1 Agustus - 31 Agustus 2021. Hari pertama mahasiswa menuju lokasi KKN untuk melapor dan memperkenalkan diri ke aparat desa. Selanjudnya mahasiswa KKN mulai melakukan setiap tahapan yang sudah direncanakan sebelumnya. Setiap minggu, mahasiswa KKN melaporkan hasil kegiatan selama satu minggu ke DPL dan DPL akan melaporkan kepada panitia. Laporan dikirim via $e$ leraning, sehingga memudahkan mahasiswa dalam mengirim laporan walaupun dalam keadaan pandemic Covid-19. Laporan yang dibuat bisa dalam bentuk narasi maupun tabel. Lampiran yang dimasukan berupa dokumentasi kegiatan dan video kegiatan yang diupload dalam yotube. Laporan akan direvisi oleh DPL dan diberikan solusi jika ada kendala dalam kegiatan.

Salah satu kegiatan yang dilaksanakan adalah melakukan bimbingan belajar dari rumah (BDR). Bimbingan belajar adalah proses pemberian bantuan kepada siswa dalam memecahkan kesulitan kesulitan yang berhubungan dengan masalah belajar (Mulyadi, 2010). Adapun fungsi dari bimbingan belajar adalah membantu siswa dalam menyelesaikan masalah yang berhubungan dengan pendidikan dan pengajaran dengan guru atau tenaga ahli (Thahir\& Hidriyanti, 2014). Bimbingan belajar yang dilaksanakan menggunakan media, pendekatan dan juga teknologi. Adapun teknologi yang digunakan dalam proses pembelajaran ialah hp android untuk menampilan video pembelajaran.

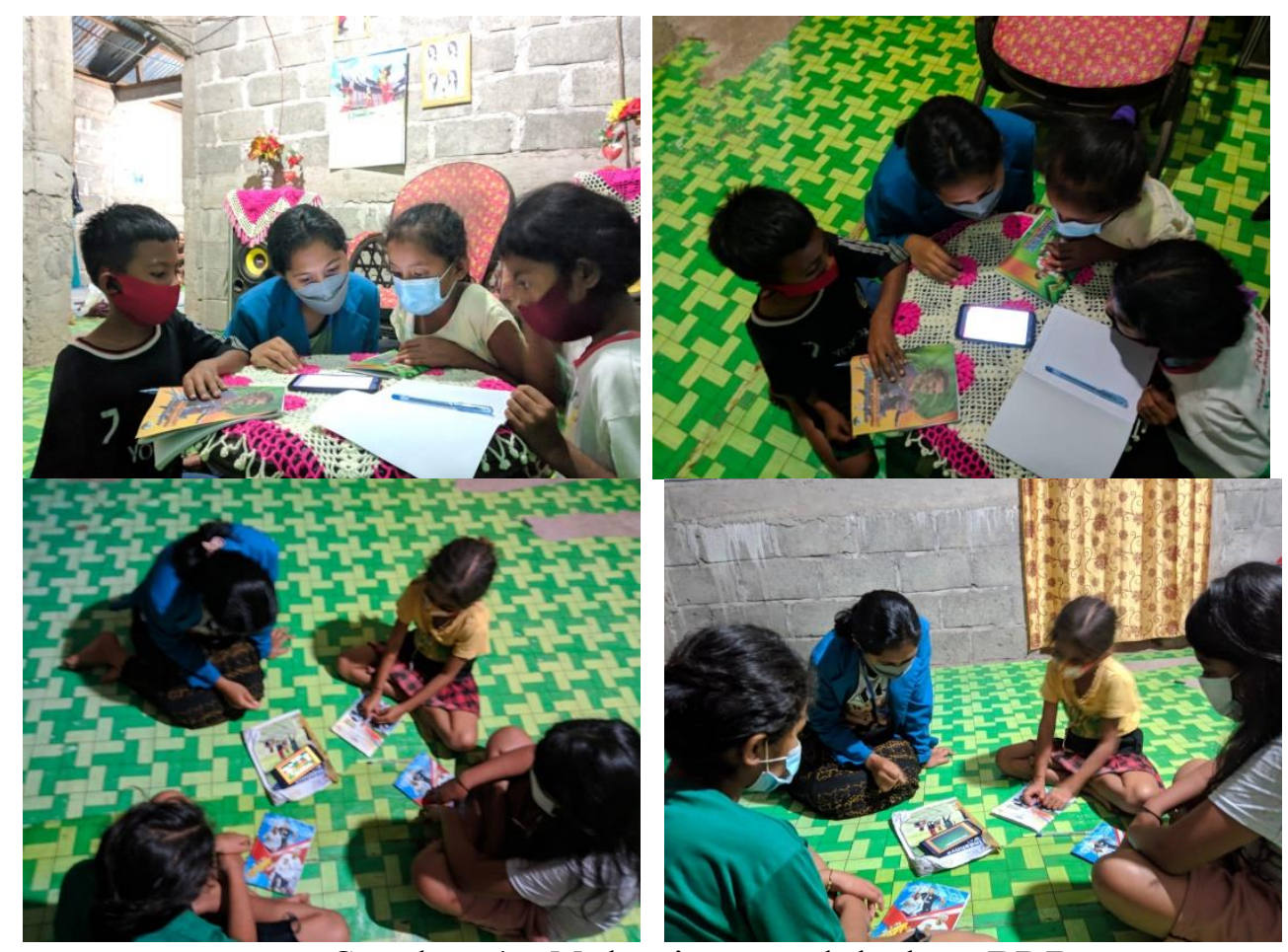

Gambar 1. Mahasiswa melakukan BDR 
Di jaman sekarang ini pemanfaatan media social seperti youtube sudah banyak digunakan sebagai media pembelajaran. Youtube sebagai media pembelajaran didalam Kurikulum 2013 sangat berguna sebagai bahan pendukung karena youtube mampu memberikan edit value terhadap pendidikan, praktis digunakan dan dapat diikuti oleh semua kalangan termasuk siswa dan guru, memberikan informasi tentang perkembangan ilmu pendidikan, teknologi, kebudayaan dan ekonomis yaitu gratis untuk semua kalangan (Huwaidah, 2019). Tentunya cara ini sangat efektif karena bentuk pembelajarannya menggunakan video yang membuat siswa lebih antusias dalam belajar dikarenakan anak jaman sekarang lebih cepat paham jika mereka menonton sesuatu ketimbang kita melakukan cerama yang membuat mereka jenuh dan bosan. Kegiatan ini tentu mendapat respon positif dari masayarakat setempat.

Kegiatan yang sudah direncanakan berikutnya ialah bimbingan belajar di salah satu sekolah dasar yakni SDI Kekawi'i yang berada di desa Ndetundora 1. Belajar dapat berjalan dengan baik jika memliki tujuan yang ingin dicapai, agar tujuan belajar dapat dicapai dibutuhkannya media pembelajaran yang dapat membantu proses belajar. Media yang digunakan mahasiswa dalam melakukan bimbingan belajar dalam mencapai tujuan belajar yaitu menggunakan media kontekstual atau nyata.
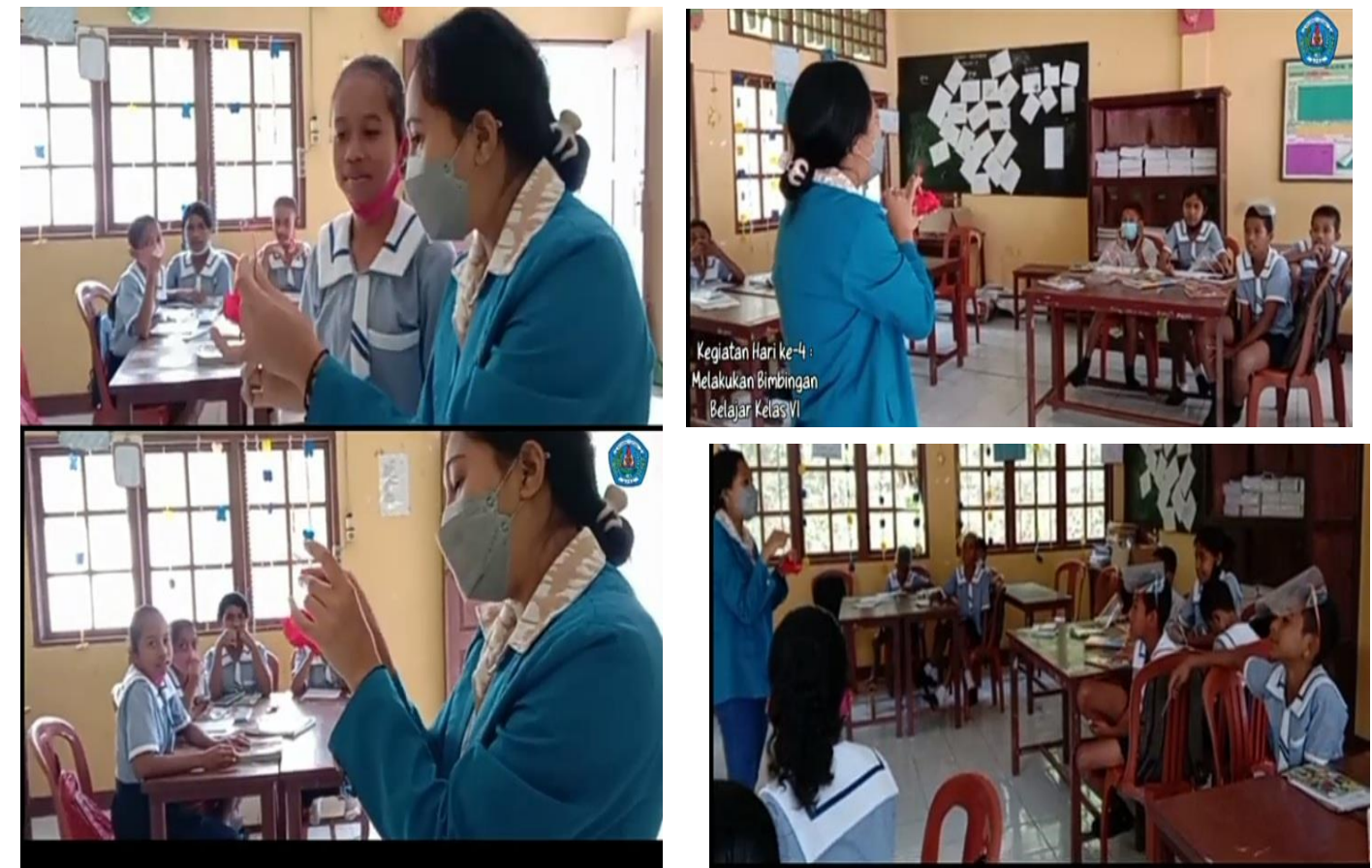

Gambar 2. Bimbngan belajar menggunakan metode demonstarsi dan media nyata

Media nyata merupakan alat bantu visual dalam pembelajaran yang berfungsi memberikan pengalaman langsung kepada siswa (Susiyanti, 2017). Menggunaan media nyata atau benda benda nyata dapat memberikan ingatan yang lebih lama bagi siswa karena siswa mendapatkan pengalaman langsung saat proses pembelajaran. 
Selanjudnya yaitu bimbingan belajar bersama siswa siwi SMP yang berada di desa setempat. Kegiatan bimbingan dengan siswa siswi SMP berlangsung selama satu minggu. Dalam bimbingan belajar siswa siwi SMP, mahasiswa menggunakan pendekatan saintifik dimana pendekatan ini membuat siswa lebih terlihat aktif dikarenakan guru hanya sebagai fasilitator saja.
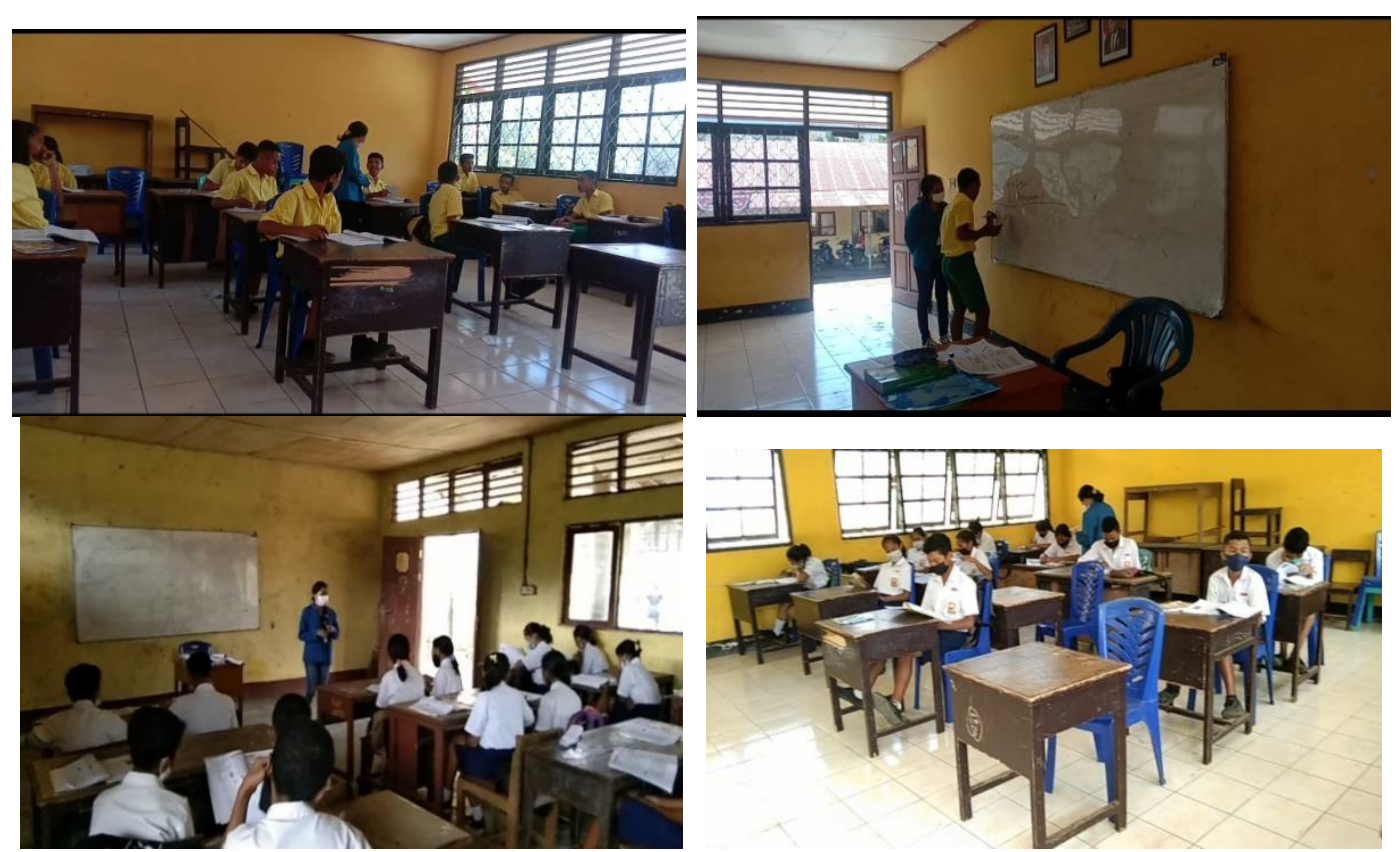

Gambar 3. Bimbingan belajar dengan menggunakan pendekatan saintifik

Secara umum pendekatan santifik memiliki langka-langka sebagai berikut yakni, mengamati, menanya, memgumpulkan informasi, melakukan percobaan, mengolah data serta mengkomunikasihkan hasil. Langkah tersebut dipakai guna memberikan pengalaman kepada siswa agar informasi yang diperoleh lebih bermakna, teruji dan dapat dipertanggungjawabkan (Setiawan, 2017).

\section{Simpulan dan Tindak Lanjut}

Pelaksanaan Kuliah Kerja Nyata mandiri (KKNM) dengan dilaksanakanya bimbingan belajar dari rumah (BDR) dan bimbingan belajar di sekolah selama berada di desa Ndetundora 1 dapat diambil kesimpulan, yakni yang pertama mahsiswa KKN mampu memberikan pengalaman belajar mahsiswa yang diperoleh selama proses perkuliahan, kedua mendapatkan respon positif dari masayarakat selama mahasiswa menjalankan program kegiatan, dan yang ketiga adanya kerja sama antara desa Ndetundora, Kecamatan Ende, Kabupaten Ende dengan Universitas Flores. Harapan selanjutnya tetap ada kerjasama yang baik antara desa Ndetundora 1 dan Universiats Flores dalam menerima mahsiswa KKN.

\section{Daftar Pustaka}

Huwaidah, A. I. (2019). pengaruh penggunaan media sosial youtube terhadap kreativitas siswa pada mata pelajaran seni budaya dan prakarya di 
sdn 1 nologaten ponorogo tahun ajaran 2018/2019 (Doctoral dissertation, IAIN Ponorogo). http://etheses.iainponorogo.ac.id/6353/

Irawanto, D. (2017). Kedudukan Ilmu Dalam Kehidupan Manusia. Pada:https://hminews-.com/2017/05/opini/kedudukan-ilmu-dalamkehidupan-manusia/

Londa, Y., Tanda, Y., Senda, Y. F., Gabe, Y. B., Banda, S. S., More, K. E. T., \& Rani, H. H. T. (2021). PENGABDIAN KKN-MANDIRI TEMATIK KELURAHAN ONEKORE KABUPATEN ENDE. Mitra Mahajana: Jurnal Pengabdian Masyarakat, 2(1), https://doi.org/10.37478/mahajana.v2i1.785

Mulyadi, H. (2010). Diagnosis kesulitan belajar dan bimbingan terhadap kesulitan belajar khusus. Yogyakarta: Nuha Litera.

Setiawan, A. R. (2018). Penerapan pendekatan saintifik untuk melatih literasi saintifik dalam domain kompetensi pada topik gerak lurus di sekolah menengah pertama. In Seminar Nasional Fisika ke-4(SiNaFi IV), Universitas Pendidikan Indonesia(UPI). https://dx.doi.org/10.13140/RG

Susiyanti, E. (2017). Penggunaan Metode Demonstrasi dan Media Nyata Untuk Meningkatkan Hasil Belajar IPA Tentang Struktur Akar Pada Siswa Kelas IV Sdn 11 Tebatkarai Kabupaten Kepahiang. Jurnal PGSD: Jurnal Ilmiah Pendidikan Guru Sekolah Dasar, 10(1), 18-21. https://doi.org/10.33369/pgsd.10.1.18-21

Thahir, A., \& Hidriyanti, B. (2014). Pengaruh Bimbingan Belajar Terhadap Prestasi Belajar Siswa Pondok Pesantren Madrasah Aliyah AlUtrujiyyah Kota Karang Bandar Lampung. KONSELI: Jurnal Bimbingan dan Konseling (E-Journal), 1(2), 55-66. http://www.ejournal.radenintan.ac.id/index.php/konseli/article/view /306 